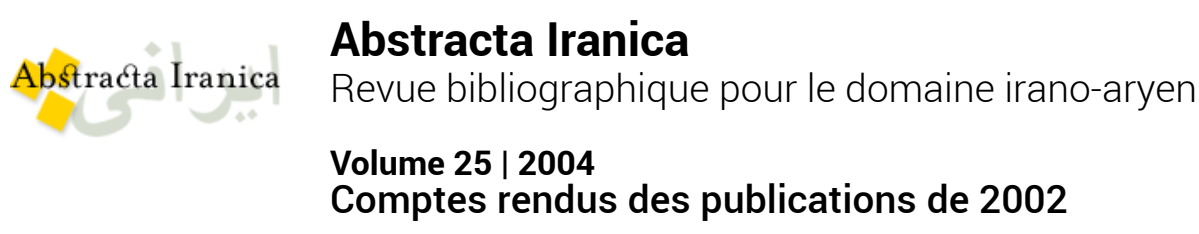

\title{
Transeuphratène, 23, (2002), 246 pages.
}

\section{Arnaud Sérandour}

\section{OpenEdition}

\section{Journals}

Édition électronique

URL : http://journals.openedition.org/abstractairanica/4307

DOI : 10.4000/abstractairanica.4307

ISSN : 1961-960X

Éditeur :

CNRS (UMR 7528 Mondes iraniens et indiens), Éditions de l'IFRI

\section{Édition imprimée}

Date de publication : 15 mai 2004

ISSN : 0240-8910

\section{Référence électronique}

Arnaud Sérandour, «Transeuphratène, 23, (2002), 246 pages. », Abstracta Iranica [En ligne], Volume 25 | 2004, document 81, mis en ligne le 15 mars 2006, consulté le 25 septembre 2020. URL : http://

journals.openedition.org/abstractairanica/4307 ; DOI : https://doi.org/10.4000/abstractairanica.4307

Ce document a été généré automatiquement le 25 septembre 2020

Tous droits réservés 


\title{
Transeuphratène, 23, (2002), 246 pages.
}

\author{
Arnaud Sérandour
}

1 Ce volume est représentatif de la collection, dévolue aux études interdisciplinaires relatives à la satrapie de Transeuphratène à l'époque achéménide. Il présente la troisième partie des actes $\mathrm{du} \mathrm{V}^{\mathrm{e}}$ Colloque international sur «la Transeuphratène à l'époque perse : religions, croyances, rites et images ", tenu à l'Institut catholique de Paris les 30-31 mars et $1^{\text {er }}$ avril 2000. Les communications traitent en majorité des religions anciennes du Levant et offrent des études portant sur des textes bibliques, des inscriptions royales ainsi que sur les représentations figurées qui se multiplient à cette époque dans l'ouest de l'Empire. Un article de A. Nunn intitulé « Images et croyances au Levant du $6^{\mathrm{e}}$ au $4^{\mathrm{e}}$ s. av. J.-C. », ouvre le volume en donnant le ton de l'ensemble des travaux dans ce domaine. L'A. étudie l'évolution sensible qu'a connue, à cette époque, l'iconographie des divers domaines de la statuaire et des reliefs, des terres cuites, de la poterie peinte, des sceaux et des monnaies. Les images ne ressortissent plus qu'à la catégorie de la protection. Elle déduit de son étude iconographique et de la lecture des textes contemporains, peu nombreux au demeurant, un changement de fonction dans la religion: désormais, ce n'est plus l'apparence du dieu qui compte, ni ses traits distinctifs, pas plus que le domaine auquel il préside traditionnellement, mais ses capacités à protéger, tout particulièrement l'individu. Cette nouvelle thématique reflète une relation nouvelle entre les hommes et les dieux. Le terrain des cultes à mystères et des religions de salut de la fin du $\mathrm{I}^{\mathrm{er}}$ millénaire n'a pas été préparé seulement en Égypte et dans les provinces de Samarie et de Judée, mais aussi sur la côte libanaise et en Syrie par un changement profond dans la perception des dieux. Il ne s'agit pas de monothéisme, qui n'existe même pas à l'état d'ébauche, au Levant achéménide. Cependant, une nouvelle orientation des rapports entre hommes et dieux se fait jour à l'époque achéménide.

2 Les études bibliques sont bien représentées par l'article de Th. Römer, «Tendances dualistes dans quelques écrits bibliques de l'époque perse ». Il est difficile d'établir une relation de causalité directe entre l'idéologie religieuse achéménide et la production 
littéraire des textes du judaïsme naissant, pourtant, l'intelligentsia juive semble avoir été influencée par le zoroastrisme officiel des Achéménides. Des tendances dualistes perceptibles dans la Bible hébraïque en ont convaincu l'A. Les auteurs sacerdotaux paraissent en effet avoir été sensibles au fait que le dieu «bon » n'a pas pu créer le mal. L'émergence de la figure du Satan dans certains textes tels que I Chroniques 21 et Job 1 est également liée à cette conception dualiste du monde. Cette nouvelle tendance théologique semble avoir été combattue par d'autres auteurs : à Isaïe 45,7, Dieu est réputé créer tant le mal que l'harmonie. Cette contradiction est interprétée par l'A. comme une polémique anti-mazdéenne.

$3 \mathrm{Au}$ nombre des études de philologie iranienne, on retiendra le résumé que livre $\mathrm{Cl}$. Herrenschmidt de sa communication intitulée: "Présentation hypothétique du mazdéisme officiel à la période achéménide ». L'A. commence par noter que les inscriptions royales achéménides manifestent une évolution du mazdéisme officiel. Elle distingue deux périodes, des premiers rois jusqu'à Artaxerxès I ${ }^{\mathrm{er}}$, puis de Darius II à la fin. Elle remarque ensuite que le mazdéisme est une religion ethnique et non universelle, qu'il est un dualisme positif opposant le parti ahourien de l'être à celui de la mort et qu'il repose sur une cosmogonie et une cosmologie fondée sur la conception du temps clos, qui place le Grand Roi au centre de l'histoire. Enfin, le mazdéisme apparaît comme une religion en partie ésotérique, dont la doctrine centrale du temps clos ne devait pas être révélée, ou le moins possible. Souhaitons que le corps de la communication soit publié intégralement dans un prochain volume de la série.

Une conclusion synthétique clôt l'ensemble, qui fait le point des contributions touchant les religions du Proche-Orient (par J. Sapin) et la Bible hébraïque (par Th. Römer) pour ouvrir sur quelques perspectives générales.

L'ouvrage se termine par quelques recensions d'ouvrages traitant principalement de la Transeuphratène à l'époque perse, une liste des adresses des contributeurs, ainsi qu'un sommaire du volume précédent, $\mathrm{II}^{\mathrm{e}}$ partie des Actes du colloque.

\section{INDEX}

Thèmes : 3.2.2. Pré-Achéménides et Achéménides

\section{AUTEURS}

ARNAUD SÉRANDOUR

Collège de France 